\title{
The effect of rabbit age on in vitro caecal fermentation of starch, pectin, xylan, cellulose, compound feed and its fibre
}

\author{
A. Lavrenčič ${ }^{\dagger}$ \\ Zootechnical Department, University of Ljubljana, Groblje 3, SI-1230 Domžale, Slovenija
}

(Received 24 May 2006; Accepted 10 September 2006)

In vitro gas production kinetics of six different substrates, pectin (PEC), xylan (XYL), starch (STA), cellulose (CEL), commercial compound feed (FEED; $201 \mathrm{~g}$ crude protein per $\mathrm{kg}$, $155 \mathrm{~g}$ crude fibre per $\mathrm{kg}$, $334 \mathrm{~g}$ neutral-detergent fibre (NDF) per $\mathrm{kg}$ and $190 \mathrm{~g}$ acid-detergent fibre (ADF) per $\mathrm{kg}$ ) and an NDF prepared from commercial compound feed (NDF FEED) were determined using the caecum contents of weaned rabbits (36 days of age) and of rabbits at slaughter age (78 days of age) as inoculums. The cumulated gas production over $96 \mathrm{~h}$ of incubation was modelled with Gompertz model, and the kinetic parameters compared. The total potential gas production (parameter ' $\mathrm{B}$ ' of the Gompertz model) was not affected $(\mathrm{P}>0.05)$ by the inoculum source, except with STA, where rabbits at slaughter weight had significantly higher total potential fermentability $(314 \mathrm{ml} / \mathrm{g}$ dry matter (DM)) than those at weaning age $(189 \mathrm{ml} / \mathrm{g}$ DM). Intensities of fermentation (maximum fermentation rate; MFR) of PEC (32.2 $\mathrm{ml} / \mathrm{h}$ ) and XYL $(24.4 \mathrm{ml} / \mathrm{h})$ were significantly greater in rabbits at weaning, while that of STA $(45 \mathrm{ml} / \mathrm{h})$ was significantly lower than at slaughter age (23.0, 14.3 and $14.0 \mathrm{ml} / \mathrm{h}$ for PEC, XYL and STA, respectively). The MFRs of CEL and NDFFEED were very similar between inoculum sources. In the first $10 \mathrm{~h}$ of fermentation which correspond to the normal retention time of the substrates in the caecum, the highest amount of gas was produced from PEC, followed by FEED and XYL. These substrates had a time of maximum fermentation rate (TMFR) at both rabbit ages short enough (8.0 and 9.5 h for PEC, 9.5 and 6.6 h for FEED, 13.7 and $14.2 \mathrm{~h}$ for XYL at weaning and at slaughter age, respectively) to be almost completely fermented in vivo.

Keywords: carbohydrates, compound feeds, fibre, in vitro digestibility, rabbits.

\section{Introduction}

In rabbits, the caecum and proximal colon are important sites of digestion. Approximately $40 \%$ of the digestible organic matter in the feed is digested in the caeco-colic segment (Gidenne, 1992). Caecal micro-organisms ferment available nutrients, mainly polysaccharides (hemicelluloses, pectins, cellulose), which cannot be digested by endogenous enzymes to short-chain fatty acids (SCFA), ammonia and gases (hydrogen, carbon dioxide and methane). Fermentation of nutrients in the caeco-colonic region of the gastro-intestinal tract (GIT) is an interaction between host (e.g. age, immune status, stress), microflora, substrates and end products of digestion. The development of the ability to ferment carbohydrates depends on the complexity of the carbohydrate and the type of bacteria dominating the microflora (Parrett et al., 1997). After the initial colonisation of the newborn animal at birth the bacterial population of the GIT remains fairly stable during suckling

\footnotetext{
${ }^{\dagger}$ E-mail: andrej.lavrencic@bfro.uni-lj.si
}

(Williams et al., 2001). Before weaning animals have colonic microflora dominated by bifidobacteria and lactobacilli. This population is characteristic for milk-fed animals and gradually changes to a bacterial population of adult animals where enterobacteriaceae and anaerobic bacteria predominate. These changes start when milk-fed animals start to consume solids (Parrett et al., 1997).

Simultaneously with the changes in bacterial populations the changes in the quantities and proportions in fermentation end products occur (Piattoni et al., 1996), which depend on the diet composition. When the diets contain carbohydrates such as pectic substances, hemicelluloses and resistant starches, which are not digested in small intestine but are fermented in large intestine (Garcia et al., 2002; Gutiérrez et al., 2002), the development of adult microflora occur during or rapidly after weaning (Gidenne and FortunLamothe, 2002). The fermentation end products, SCFA, promote water and $\mathrm{Na}$ absorption, thus preventing osmotic diarrhoea in situations of small intestinal malabsorption of sugars (Edwards, 1993). SCFA may also have other beneficial effects in the colonic lumen as they serve as 
energy source for colonic mucosa cells and increase cellular proliferation of the colonic epithelia (Williams et al., 2001). However, Canas-Rodriguez and Smith (1966) and Marounek et al. (1999) reported that the intake of rabbit milk can negatively affect caecum fermentation as milk fat octanoic and decanoic acid show antimicrobial activity.

When large amounts of cellulose and other non-digestible and non-fermentable nutrients (lignin) are included in the diets of non-ruminant animals the fermentation activity in the caecum during or after weaning is poorly developed and unabsorbed and unfermented carbohydrates are likely to increase stool output which has several nutritional implications. Increased faecal mass includes an increased loss of nitrogen, energy, water and electrolytes (Edwards, 1993). However, Edwards (1993) reported also some favourable effects of low fermentable carbohydrates such as increased loss of bile acid metabolites and other potentially toxic substances which may decrease the risk of mucosal damage and alter the bile acid pool.

Fermentative activity of caecum micro-organisms could be estimated using different methods. In the past, the microbial counts were often used for determination and quantification of (pathogenic) micro-organisms in the caecum and large intestine (Williams et al., 2001). However, with this technique we could measure only the activity of individual bacterial species. More often we are interested in the activity of whole bacterial population. This could be achieved with methods where the production rates of microbial protein (ATP production rate; Venkateswaran et al. (2003)) and/or fermentation end products such as volatile fatty acid (VFA) (Kermauner et al., 1996; Marounek et al., 1999; Gidenne et al., 2002) are measured. The whole microbial population activity could be measured also with the measurements of accumulating gas at different incubation times (Menke and Steingass, 1988; Williams et al., 2001). The technique is carried out under strictly anaerobic conditions and is being used to examine the activity of the microflora from many different sources, including the rumen (Theodorou et al., 1994; Getachew et al., 1998; Lavrenčič and Stefanon, 2001) and GIT and faeces of pigs (Bauer et al., 2004; Awati et al., 2005; Bindelle et al., 2007a and b). On the contrary, this technique was rarely used to study the microbial fermentation activity in the caecum of rabbits (Calabro et al., 1999).

The objectives of this work were to extend the knowledge on the microbial activity in the caecum by using the in vitro gas production technique, employing the rabbit caecum content as inoculum (Piattoni et al., 1996; Marounek et al., 1997, 1999, 2000a and b), to study the effect of substrate on the gas production kinetics and to extend the knowledge on the effect of rabbit age on fermentation activity in the caecum. For this purpose, different starting substrates were used to look at shifts in microbial fermentation which are associated with the development of microbial populations from weaning, when the microbial activity is still influenced by rabbit milk, to slaughter, when microbial population is fully adapted to the offered diet.
Thus the caecum contents of weaned ( 36 days of age) and adult (78 days) rabbits were chosen to prepare the inoculums for in vitro gas production measurements.

\section{Material and methods}

\section{Substrates}

Six different substrates were chosen to reflect a range of complex carbohydrates which are constituents of the commercial compound feeds and their neutral-detergent fibres (NDFs). Starch (STA; soluble potato starch for determination of $\alpha$-amylase (diastase) activity, Art. No. 101252, Merck, Darmstadt, Germany), apple pectin (PEC; 75\% galacturonic acid and 8.6\% methoxyl groups; Art No. P-8471, Sigma, Germany), xylan from oat spelts (XYL; poly$\beta[1,4]$-D-xylopyranose; $86 \%$ xylose, $10 \%$ arabinose and $4 \%$ glucose residues; Art. No. X-0627, Sigma, Germany), cellulose (CEL; BWW 40; 99.5\% cellulose and 0.3\% ash, fibre length app. $200 \mu \mathrm{m}$; J. Rettenmaier and Söhne, Germany), commercial compound feed (FEED) for rabbits after weaning (proximal chemical composition on a drymatter (DM) basis was $(\mathrm{g} / \mathrm{kg})$ : crude protein 201 , fat 22 , crude fibre 155, ash 98, nitrogen-free extract 524, NDF 334, acid-detergent fibre (ADF) 190, acid-detergent lignin (ADL) 51; Krka, Novo mesto, Slovenia) and the NDF prepared from the compound feed (NDF FEED).

The NDF was prepared according to the modified method of Stefanon et al. (1996). The compound feed was weighed $(1 \mathrm{~g})$ into a $250 \mathrm{ml}$ beaker and boiled in $100 \mathrm{ml}$ of neutral detergent solution at $105^{\circ} \mathrm{C}$ for $1 \mathrm{~h}$. The extracted fibre was filtered through a $50 \mu \mathrm{m}$ mesh nylon bag and washed several times with hot distilled water and then rinsed with ethanol and acetone. The bags were then dried at $45^{\circ} \mathrm{C}$ until they were almost dry and incubated overnight at room temperature in $1 \mathrm{~mol} / \mathrm{l}$ ammonium sulphate to remove any trace of ionically bound detergent. The wash with ethanol and acetone was repeated and then the fibre was dried overnight at $45^{\circ} \mathrm{C}$.

\section{In vitro fermentation}

Manipulations and selection of animals and the preparation of inoculum were performed according to the methods used by Calabro et al. (1999). Freshly collected samples of the caecum content were used to prepare the inoculum. Two 78-day-old and three 36-day-old New Zealand White rabbits (Slovenian meat line SIKA) showing normal weight gain were randomly chosen prior to slaughtering and were fed the commercial compound feed also used as substrate (FEED). The diet was offered ad libitum from weaning at 35 days of age. Rabbits sacrificed at 36 days of age also received milk, as they were weaned just before slaughter. The feed was removed at $1800 \mathrm{~h}$ on the day before sampling, but water was still available ad libitum.

The animals were sacrificed at about $0800 \mathrm{~h}$ and the caecums were isolated by tying off the two extremities with nylon string to prevent movement of the digesta and transported to the laboratory within $10 \mathrm{~min}$ in a 
prewarmed $\left(39^{\circ} \mathrm{C}\right)$ container. Afterwards the caecum contents were mixed together in $200 \mathrm{ml}$ beaker. Depending on the number of syringes, the exact quantity of caecum contents was weighted into another $200 \mathrm{ml}$ beaker placed on the balance and diluted with $150 \mathrm{ml}$ of a buffer solution prepared according to Menke and Steingass (1988; Table 1). The suspension was then squeezed through four layers of cotton gauze into a 21 flask where was the remaining buffer. The dilution of caecum contents in the buffer solution was equal to $1: 50(\mathrm{w} / \mathrm{v} ; 0.2 \mathrm{~g}$ caecum contents per $\mathrm{ml}$ buffer solution). All manipulations (mixing, weighting, diluting, filtering through gauze and constitution of inoculum) and the filling of syringes were done under the constant flushing of the oxygen free $\mathrm{CO}_{2}$ gas to assure anaerobic conditions and the temperature was always kept at $39.0^{\circ} \mathrm{C}$. All syringes were filled in no more than 40 min after the slaughtering.

In vitro gas production was determined according to the procedure described by Menke and Steingass (1988). One hundred and seventy five milligrams of substrate were anaerobically incubated at $39^{\circ} \mathrm{C}$ in duplicate in a $100 \mathrm{ml}$ glass syringe containing $30 \mathrm{ml}$ of inoculum. The production of gas resulting from microbial fermentation was measured manually by reading the position of the bottom end (marked with line) of the piston after $0,2,4,6,8,10,12$, $24,36,48,72$ and $96 \mathrm{~h}$. The incubation of samples in each inoculum was repeated twice. In each repetition two syringes with blank samples (syringes without substrate) were also incubated. The net amount of gas produced at each incubation time was calculated by subtraction of the average amount of gas produced from blank samples at corresponding incubation time.

\section{Calculations and statistical analysis}

The values of gas produced at different times of incubation from inoculums prepared from the caecum contents of 36and 78-day-old rabbits were corrected for the amount of gas produced from blank samples at the corresponding times within each repetition and type of inoculum. These values were also corrected for the DM contents of samples.

Table 1 Composition of buffer solutions (Menke and Steingass, 1988)

\begin{tabular}{lc}
\hline \hline+ & Concentration in buffer $(\mathrm{ml} / \mathrm{l})$ \\
\hline Solution A & 238 \\
Solution B & 238 \\
Trace mineral solution & 0.12 \\
Resazurin & 1.22 \\
Reduction solution & 47.5 \\
Distilled water & 476 \\
\hline
\end{tabular}

\footnotetext{
${ }^{\dagger}$ Solution A composition (g/l): $\mathrm{NaHCO}_{3} 35.0 ;\left(\mathrm{NH}_{4}\right) \mathrm{HCO}_{3}$ 4.0. Solution B composition (g/l): $\mathrm{Na}_{2} \mathrm{HPO}_{4} 5.7 ; \mathrm{KH}_{2} \mathrm{PO}_{4} 6.2 ; \mathrm{MgSO}_{4} .7 \mathrm{H}_{2} \mathrm{O} 0.6$. Trace mineral solution composition (g/100 ml): $\mathrm{CaCl}_{2} \cdot 2 \mathrm{H}_{2} \mathrm{O} 13.2 ; \mathrm{MnCl}_{2} .2 \mathrm{H}_{2} \mathrm{O}$ 10.0; $\mathrm{CoCl}_{2} .2 \mathrm{H}_{2} \mathrm{O}$ 1.0; $\mathrm{FeCl}_{2} .2 \mathrm{H}_{2} \mathrm{O}$ 0.8. Resazurin composition $(\mathrm{mg} / 100 \mathrm{ml}): 100 \mathrm{mg}$. Reduction solution: $1 \mathrm{~mol} / / \mathrm{NaOH} 2 \mathrm{ml} ; \mathrm{Na}_{2} \mathrm{~S} .7 \mathrm{H}_{2} \mathrm{O} 285 \mathrm{mg}$; distilled water $47.5 \mathrm{ml}$.
}

The values corrected in such a manner were then fitted to the Gompertz model (Bidlack and Buxton, 1992; Lavrenčič et al., 1997):

$$
Y_{t}=B \times e^{-C \times e^{-A t}}
$$

where $Y_{t}$ is the gas produced $(\mathrm{ml} / \mathrm{g} \mathrm{DM})$ at time $t, B$ is the asymptotic amount of the produced gas (maximum amount of produced gas or total potential gas production; $\mathrm{ml} / \mathrm{g}$ DM), $C$ is the specific gas production rate as affected by $t$ and is governed by a constant $A$ describing the decay in specific gas production rate (caused by diminishing growth rate of microorganisms and increasing substrate limitation as reflected in gas production; Beuvink and Kogut, 1993), and $t$ is time in $\mathrm{h}$. Parameter values and curve fitting were estimated by the Marquard compromise of a non-linear regression method, using software (Proc NLIN) (Statistical Analysis Systems Institute (SAS), 1994).

The variation in gas production rates was obtained by calculating the first derivative of the Gompertz model with respect to the time of incubation:

$$
\frac{d Y}{d t}=B \times C \times A \times e^{-A t} \times e^{-C \times e^{-A t}}
$$

The time of maximum fermentation rate (TMFR; $h$ ) was calculated by setting the second derivative of the Gompertz model equal to 0 and solving for $t$.

$$
\begin{aligned}
\frac{d^{2} Y}{d t^{2}}= & A \times B^{2} \times C^{2} \times\left(e^{-A t}\right)^{2} \times e^{-C \times e^{-A t}} \\
& -A \times B \times C^{2} \times e^{-C \times e^{-A t}}=0
\end{aligned}
$$

The maximum fermentation rate (MFR; $\mathrm{ml} / \mathrm{h}$ ) was then calculated by inserting the corresponding TMFR value into the first derivative equation.

The delay in fermentation at the start of incubation (LAG; h) was obtained from the equation:

$$
L A G=\frac{\log (C)-1}{A}
$$

Data concerning fermentation kinetic parameters (parameters $B, C, A, L A G$, MFR and TMFR) were tested for significance by analysis of variance using the Scheffe test.

$$
Y_{i j k}=\mu+A_{i}+S_{j}+A S_{i j}+e_{i j k}
$$

where $Y_{i j k}$ is the value, $\mu$ the mean, $A_{i}$ the effect of rabbit age, $S_{j}$ the effect of incubated substrate, $A S_{i j}$ the interaction between rabbit age and substrate and $e_{i j k}$ the residual errors. All statistical analyses were performed using the of GLM procedure of the SAS (1994).

\section{Results}

The estimated parameters of in vitro gas production of the various substrates are reported in Table 2 where the main effects of substrate and rabbit age are also presented. The estimated fermentation kinetic parameters of different substrates were significantly different $(P<0.001)$. There 
were also significant differences in fermentation kinetic parameters $(P<\leq 0.001)$ according to the age of rabbits, except in parameter $A$. Furthermore, there were significant interactions $(P<0.001)$ between substrate and rabbit age for all estimated fermentation kinetic parameters.

The total potential gas production (parameter $B$ ) varied from $75 \mathrm{ml} / \mathrm{g}$ for NDF FEED to $356 \mathrm{ml} / \mathrm{g}$ for PEC. Both values were obtained using inoculums prepared from 36-day-old rabbits (CC-36). Similarly, the values of parameter $C$ varied substantially and were the lowest for FEED (3.87) and highest for CEL (51.10) when both were incubated in CC-36. The values of parameter $A$ ranged from 0.0636 for CEL incubated in the inoculums prepared from caecum contents of 78-day-old rabbits (CC-78) to 0.246 for PEC incubated in CC-36.

Within substrates the differences in total potential gas production of PEC, XYL and FEED were higher when CC-36 was used, while for other substrates (STA, CEL and $\mathrm{NDF}_{\mathrm{FEED}}$ ) the total potential gas productions were generally higher when CC-78 was used, but the differences between the two types of inoculums were significant $(P<0.05)$ only for STA. Age of rabbits affected significantly $(P<0.05)$ only the XYL and CEL specific fermentation rate (parameter $C$ ), which were higher when CC-36 was used. The parameters $A$ of $X Y L$ and FEED were significantly $(P<0.05)$ higher and lower, respectively, when CC-36 was

Table 2 Parameters of the Gompertz model of starch (STA), pectin $(P E C)$, xylan (XYL), cellulose (CEL), commercial compound feed (FEED) and its NDF (NDF FEED) obtained with the in vitro gas production in the inoculum prepared from the caecum content of 36and 78-day-old rabbits

\begin{tabular}{lcccl}
\hline \hline Substrate & Age $^{\dagger}$ (days) & $B^{\ddagger}(\mathrm{ml} / \mathrm{g} \mathrm{DM})$ & $C^{\ddagger}$ & $A^{\ddagger}$ \\
\hline STA & 36 & $189^{\mathrm{c}}$ & $5.83^{\mathrm{c}}$ & $0.065^{\mathrm{de}}$ \\
& 78 & $314^{\mathrm{ab}}$ & $8.49^{\mathrm{c}}$ & $0.121^{\mathrm{cde}}$ \\
PEC & 36 & $356^{\mathrm{a}}$ & $7.40^{\mathrm{c}}$ & $0.246^{\mathrm{a}}$ \\
& 78 & $331^{\mathrm{ab}}$ & $6.00^{\mathrm{c}}$ & $0.189^{\mathrm{ab}}$ \\
XYL & 36 & $311^{\mathrm{ab}}$ & $18.52^{\mathrm{b}}$ & $0.213^{\mathrm{a}}$ \\
& 78 & $307^{\mathrm{b}}$ & $5.98^{\mathrm{c}}$ & $0.126^{\mathrm{cd}}$ \\
CEL & 36 & $115^{\mathrm{de}}$ & $51.10^{\mathrm{a}}$ & $0.094^{\mathrm{cde}}$ \\
& 78 & $155^{\mathrm{cd}}$ & $13.60^{\mathrm{bc}}$ & $0.064^{\mathrm{e}}$ \\
FEED & 36 & $179^{\mathrm{c}}$ & $3.87^{\mathrm{c}}$ & $0.142^{\mathrm{bc}}$ \\
& 78 & $143^{\mathrm{cd}}$ & $4.13^{\mathrm{c}}$ & $0.215^{\mathrm{a}}$ \\
NDF & 36 & $75^{\mathrm{e}}$ & $7.40^{\mathrm{c}}$ & $0.123^{\mathrm{cde}}$ \\
& 78 & $92^{\mathrm{e}}$ & $6.35^{\mathrm{c}}$ & $0.124^{\text {cde }}$ \\
RMSE & & 8.7 & 1.790 & 0.0113 \\
Statistical significance & & & & \\
Age & & $* * *$ & $* * *$ & \\
Substrate & & $* * *$ & $* * *$ & $* * *$ \\
Age $\times$ substrate & & $* * *$ & $* * *$ & $* * *$ \\
\hline \hline
\end{tabular}

$\mathrm{a}, \mathrm{b}, \mathrm{c}, \mathrm{d}, \mathrm{e}=$ Means in columns with different superscripts are significantly different at the level $P=0.05$.

${ }^{\dagger}$ Age of rabbits - caecum content donors (36 or 78 days).

${ }^{\mp} B=$ asymptotic amount of the produced gas (maximum amount of produced gas or total potential gas production); $C=$ specific gas production rate as affected by $t$, and is governed by a constant $A ; A$ describes the decay in specific gas production rate.

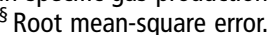

used, while within other substrates $A$ did not differed between inoculums.

Apart from the estimated parameters of gas production (parameters $B, C$ and $A$ ) additionally calculated parameters such as the delay of fermentation at the start of incubation (LAG), maximum fermentation rate (MFR) and time of maximum fermentation rate (TMFR) helped to describe better the fermentation pattern of the substrates. They are presented in Table 3 and Figures 1-6. All these parameters were affected significantly by age and substrate $(P<0.05)$. Furthermore, there were significant interactions between age and substrate with all calculated parameters. The shortest LAG was obtained for FEED (1.9h) when CC-78 was used, while the longest was obtained for CEL (31.2 h) when CC-36 was used. The LAGs were generally shorter when CC-78 was used, but the differences between the two types of inoculums were significant $(P<0.05)$ only for CEL.

Both the lowest and the highest MFR were calculated when CC-36 was used. The lowest MFR was obtained for NDF FEED $_{\text {F }}(3.4 \mathrm{ml} / \mathrm{h}$; Table 3 and Figure 6$)$, while the highest MFR was for PEC (32.2 $\mathrm{ml} / \mathrm{h}$; Table 3 and Figure 1). The MFRs were higher for PEC $(P<0.05), \mathrm{XYL}(P<0.05)$ and FEED $(P>0.05)$ incubated in CC-36, while those for STA $(P<0.05)$, CEL $(P>0.05)$ and $\mathrm{NDF}_{\mathrm{FEED}}(P>0.05)$ were higher when CC-78 was used. The greatest difference

Table 3 Maximum fermentation rate (MFR), times of maximum fermentation rate (TMFR) and lag phase (LAG) of starch (STA), pectin $(P E C)$, xylan (XYL), cellulose (CEL), commercial compound feed (FEED) and its NDF (NDF FEED) obtained with the in vitro gas production in the inoculum prepared from the caecum content of 36- and 78-day-old rabbits

\begin{tabular}{lcccc}
\hline \hline Substrate & $\mathrm{Age}^{\dagger}$ (days) & $\mathrm{MFR}^{\ddagger}(\mathrm{ml} / \mathrm{h})$ & $\mathrm{TMFR}^{\ddagger}(\mathrm{h})$ & $\mathrm{LAG}^{\ddagger}(\mathrm{h})$ \\
\hline STA & 36 & $4.5^{\mathrm{de}}$ & $27.6^{\mathrm{b}}$ & $12.0^{\mathrm{c}}$ \\
& 78 & $14.0^{\mathrm{c}}$ & $17.7^{\mathrm{c}}$ & $9.4^{\mathrm{cd}}$ \\
PEC & 36 & $32.2^{\mathrm{a}}$ & $8.0^{\mathrm{fg}}$ & $3.9^{\mathrm{fg}}$ \\
& 78 & $23.0^{\mathrm{b}}$ & $9.5^{\mathrm{f}}$ & $4.2^{\mathrm{fg}}$ \\
XYL & 36 & $24.4^{\mathrm{b}}$ & $13.7^{\mathrm{e}}$ & $9.0^{\mathrm{cde}}$ \\
& 78 & $14.3^{\mathrm{c}}$ & $14.2^{\mathrm{de}}$ & $6.2^{\text {ef }}$ \\
CEL & 36 & $4.0^{\mathrm{de}}$ & $41.8^{\mathrm{a}}$ & $31.2^{\mathrm{a}}$ \\
& 78 & $3.6^{\mathrm{de}}$ & $40.7^{\mathrm{a}}$ & $24.9^{\mathrm{b}}$ \\
FEED & 36 & $9.4^{\mathrm{cd}}$ & $9.5^{\mathrm{f}}$ & $2.5^{\mathrm{g}}$ \\
& 78 & $11.3^{\mathrm{c}}$ & $6.6^{\mathrm{g}}$ & $1.9^{\mathrm{g}}$ \\
NDF & 36 & $3.4^{\mathrm{e}}$ & $16.3^{\mathrm{cd}}$ & $8.1^{\mathrm{de}}$ \\
& 78 & $4.2^{\mathrm{de}}$ & $14.9^{\mathrm{de}}$ & $6.8^{\mathrm{def}}$ \\
RMSE & & 1.08 & 0.46 & 0.57 \\
Statistical significance & & & & \\
Age & & $*$ & $* * *$ & $* * *$ \\
Substrate & & $* * *$ & $* * *$ & $* * *$ \\
Age $\times$ substrate & & $* * *$ & $* * *$ & $* * *$ \\
\hline
\end{tabular}

$\overline{a, b, c, d, e, f, g}=$ Means in columns with different superscripts are significantly different at the level $P=0.05$.

${ }^{\dagger}$ Age of rabbits - caecum content donors (36 or 78 days).

${ }^{\ddagger} \mathrm{MFR}=$ maximum fermentation rate $(\mathrm{ml} / \mathrm{h}) ; \mathrm{TMFR}=$ time of maximum fermentation rate $(\mathrm{h})$; Lag $=$ lag time $(\mathrm{h})$.

$\S$ Root mean square error. 


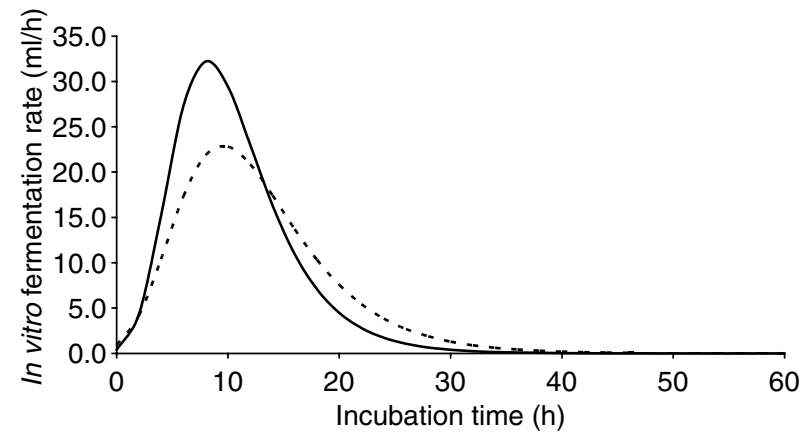

Figure 1 In vitro PEC fermentation rate in the inoculum prepared from caecum contents of $36(-)$ and 78 (- - -) day old rabbits.

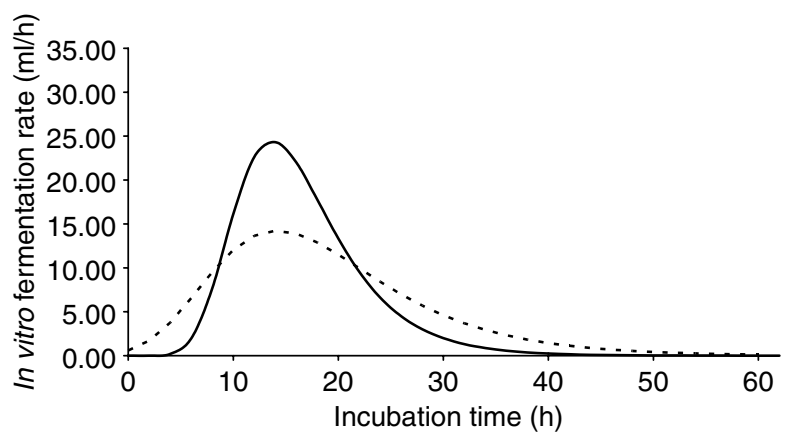

Figure 2 In vitro XYL fermentation rate in the inoculum prepared from caecum contents of 36 ( - ) and 78 (- - -) day old rabbits.

between the two types of inoculums within each substrate was calculated for $\mathrm{XYL}(10.1 \mathrm{ml} / \mathrm{h}, P<0.05$; Figure 2), while the smallest difference was observed for CEL $(0.4 \mathrm{ml} /$ $\mathrm{h}$; Figure 5).

The shortest TMFR was obtained for FEED (6.6 h) incubated in CC-78, while the longest was observed for CEL $(41.8 \mathrm{~h}$ ) incubated in CC-36 (Table 3). When the TMFRs between both inoculums within each substrate were compared, both PEC and XYL had non-significantly $(P>0.05)$ shorter TMFRs when CC-36 was used $(8.0$ and $9.5 \mathrm{~h}$ for PEC and 13.7 and $14.2 \mathrm{~h}$ for XYL when CC-36 and CC-78 were used, respectively; Figures 1 and 2). For other substrates (STA, CEL, FEED and NDF FEED) TMFRs were longer when CC-36 was used. The greatest significant

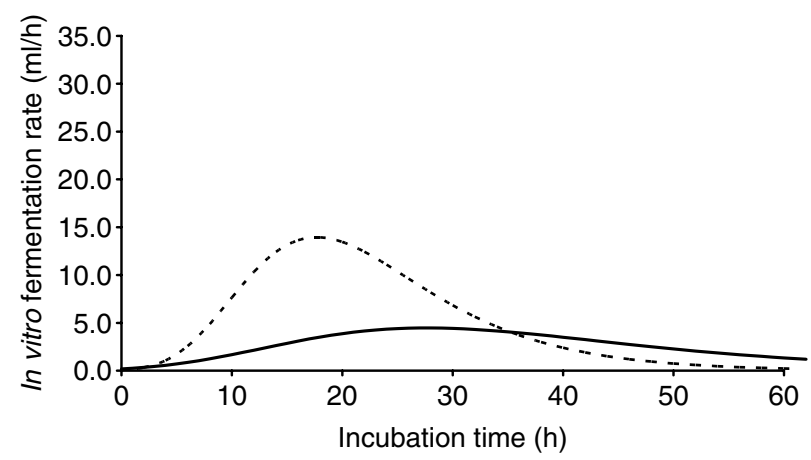

Figure 3 In vitro STA fermentation rate in the inoculum prepared from caecum contents of $36(-)$ and $78(--)$ day old rabbits.

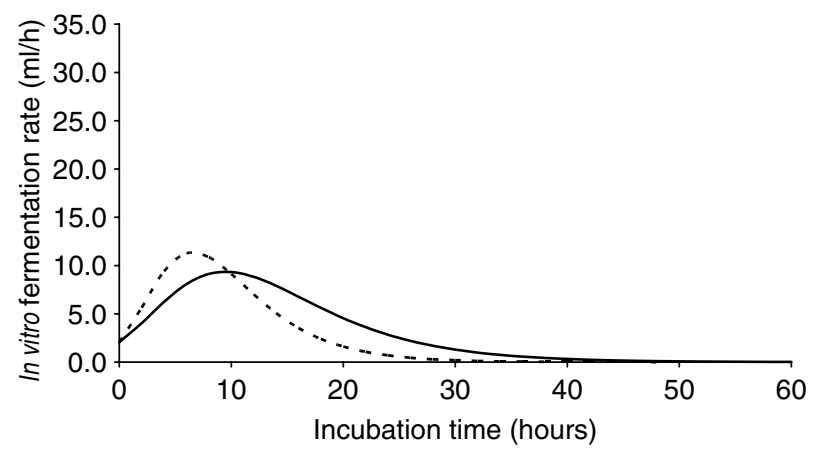

Figure 4 In vitro FEED fermentation rate in the inoculum prepared from caecum contents of 36 (-) and 78 (- - -) day old rabbits.

difference was calculated for STA $(9.9 \mathrm{~h} ; P<0.05$; Figure 3). Other significant difference $(P<0.05)$ was also observed for FEED (2.9 h; Figure 4).

\section{Discussion}

The processes of digestion occurring in vitro will never be identical to those occurring in vivo. The inoculums for the in vitro studies are normally made with the contents from a specific part of the GIT, such as caecum or colon, or with the faeces (Calabro et al., 1999; Bauer et al., 2004) and do not represent the whole microbial population of the gut, its activity and/or a diversity of environmental conditions in the different sections of the digestive tract. In addition, the buffer solution used for the inoculum preparation for in vitro fermentation often contains some nutrients (e.g. nitrogen, macro and microelements), which are not present in large amounts in the contents of large intestine sections. This means that in vivo fermentation capacity is always lower than that in vitro. However, even if the diversity of various conditions cannot be fully reproduced by in vitro methods, Bauer et al. (2004) and Bindelle et al. (2007a and b) stated that the gas production technique could be used to characterise feed fermentation in the large intestine of non-ruminant animals and that the ranking of in vitro fermentative characteristics of substrates would probably remain the same as it is in vivo.

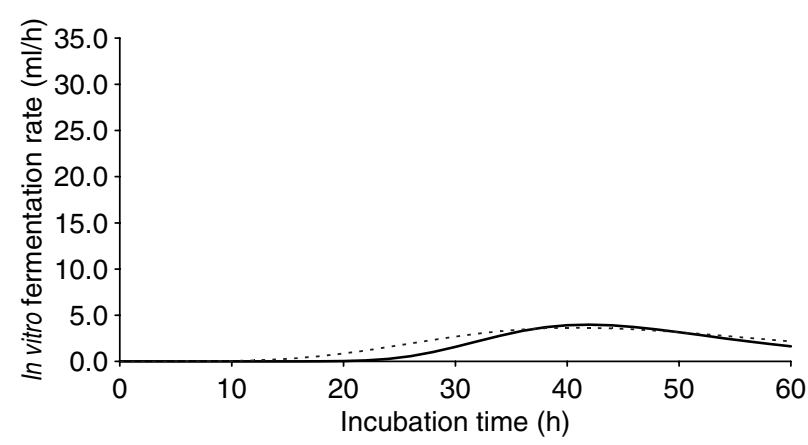

Figure 5 In vitro CEL fermentation rate in the inoculum prepared from caecum contents of $36(-)$ and 78 (- - -) day old rabbits. 


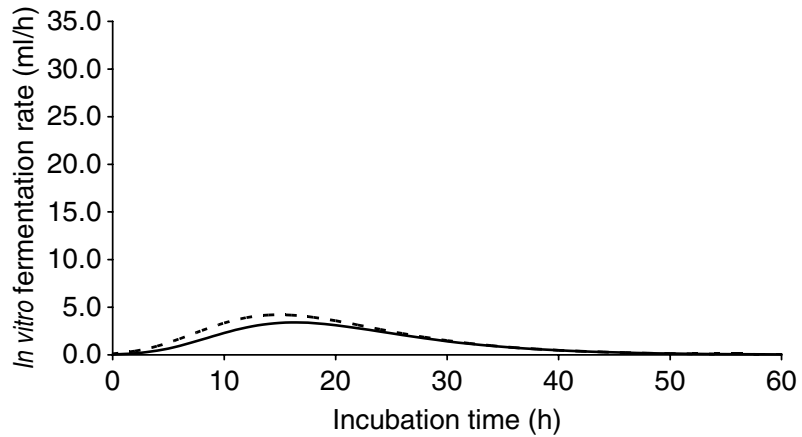

Figure 6 In vitro NDF FEED fermentation rate in the inoculum from caecum contents of $36(-)$ and 78 (- - -) day old rabbits.

\section{Effect of substrate}

Blümmel et al. (1997) and Getachew et al. (1998) reported that amount of gas produced in in vitro fermentation is directly related to the amount of SCFA production. This suggests that using substrates from which large amounts of gas are produced, such as PEC and XYL in current study, leads to large production of SCFA, which decreases the caecal pH. Garcia et al. (2002) reported that dietary pectins (uronic acids) are the only dietary chemical constituent related to caecal pH and Gidenne (1997) reported that caecal $\mathrm{pH}$ is related with the health status of the growing animal. Results presented in Table 2 suggest that large amounts of SCFA will be produced (with consequent reduction of caecal $\mathrm{pH}$ ) also when XYL and partially FEED and STA will be fermented. These substrates had also relatively high MFRs (Table 3 and Figures 1-4), while the fermentation rates of other substrates (CEL and NDF FEED $_{\text {) }}$ were much lower (less than $3.8 \mathrm{ml} / \mathrm{h}$ ).

However, only with the values of total potential gas production and MFRs we cannot estimate the importance of individual feeds or nutrients in vivo, because the retention time of substrates in the caecum is limited to about $10 \mathrm{~h}$ (Gidenne et al., 2002). Within this time only FEED and PEC reached their MDRs. FEED and PEC had very similar TMFRs and LAGs, which most probably derived from sugar-beet pulp and dehydrated alfalfa, which contain considerable amounts of pectins and are important ingredients of rabbit compound feeds.

Hemicelluloses (e.g. XYL) are important ingredients of rabbit compound feeds and are also important substrates for intestinal microbes (Gidenne et al., 2000 and 2002; Gidenne and Fortun-Lamothe, 2002), although the obtained TMFR of XYL was longer than the estimated retention time in the caecum. We suppose that TMFRs (and LAGs) of XYL and other substrates in vivo are shorter because the in vitro fermentation is affected by the dilution of the inocula and the time needed for hydration and microbial colonisation of substrates, before the fermentation starts. Bindelle et al. (2007a) reported that the dilution of inocula in the buffer solution had no effect on the final amount of produced gas but influenced the lag time and the fermentation rates. Longer LAGs and TMFRs may be related to decreasing concentrations of active bacteria in the inoculum and to the presence of nutrients in the inoculum to which micro-organisms are adapted. In in vivo fermentation the substrates are already hydrated and colonized with microbes when they reach the caecum, thus the LAGs and TMFRs should be much shorter than those presented in Table 3.

Linkages between cell wall components, especially between lignin and polysaccharides (Akin and Chesson, 1989; Hatfield, 1989) limit physical access of microbes to cell wall (Wilson, 1994). This is the main reason why the polysaccharides of intact cell walls have different fermentation patterns than the same constituents purified from plant cell walls (e.g. cellulose, xylan or pectic substances). This means that the results of the current study should be used with caution if the fermentation of polysaccharides of intact cell walls is studied.

Starch is an important nutrient of compound feeds for rabbits, accounting for about $200 \mathrm{~g} / \mathrm{kg}$ on DM. Some controversy is present on the effect of starch on caecal microbial fermentation. Blas et al. (1994) suggested that a significant proportion of maize starch escaped digestion in the small intestine causing undesirable fermentation and growth of caecal microflora, which led to increased mortality of rabbits. In addition, Gutiérrez et al. (2002) found that replacement of wheat starch with peas, led to a significant increase in starch concentration at the terminal ileum. They mentioned that the most of this starch was fermented at the caecum. Moreover, Padilha et al. (1995) found high counts of amilolytic micro-organisms in the caecum and indicated that caecal microbes are able to digest starch. On the contrary, several experiments (Gidenne et al., $2000,2004 a$ and $b$ and 2005) showed that starch is extensively digested in the small intestine and that only small amounts of starch reach the caecum. These authors concluded that starch could not significantly affect fermentative activity in the caecum. In the current study we found that starch is fermented in vitro if we used the inoculum prepared from caecum contents, however, we observed that STA had long lag phase $(10.7 \mathrm{~h})$ and TMFR $(22.6 \mathrm{~h})$ and only negligible amounts of gas $(15 \mathrm{ml})$ were produced during the mean retention time of $10 \mathrm{~h}$ in the caecum. Similar length of TMFR (11.6 and 14.6h) was determined also by Awati et al. (2005), who performed gas production test with wheat starch using faeces of pigs as inoculum. Even if we suppose that these LAGs and TMFRs in vivo are shorter, they are still too long to permit extensive starch fermentation in the caecum, confirming the findings of Gidenne et al. (2000, 2004a and b and 2005) that starch is not an important substrate for caecal micro-organisms.

\section{Effect of rabbit age}

The total potential gas production of used substrates, with exception of STA, did not differ significantly $(P<0.05)$ between rabbit ages (Table 2). This is in agreement with the results of Bindelle et al. (2007b) who obtained similar results incubating sugar-beet fibre in inoculum prepared 
from the faeces of young, growing and adult pigs. Awati et al. (2005) mentioned that the whole microbial community present in the inoculum adapts to the substrate during fermentation and reaches the maximum gas production, whatever the substrate, after less than $48 \mathrm{~h}$ of incubation. However, we found that CEL reached total potential gas production only after about $72 \mathrm{~h}$ of incubation.

The fermentation kinetics differences are attributable to the composition of microbial community present in the collected caecum contents and to its activity. Because the enzymatic system of the rabbit, weaned between 30 and 35 days of age, is not yet fully developed at weaning (Gidenne and Fortun-Lamothe, 2002), some nutrients pass undigested through the small intestine into the caecum, where they serve as a substrate for caecum microflora, which is established already in the 2nd week of life. The bacterial population increases steadily with age and reaches stable levels around weaning (Bennegadi et al., 2003). At day 25 the microbial pectinolytic and xylanolytic activities are high and reach 64 and $68 \%$ of the activity observed at day 44, respectively (Gidenne et al., 2002). In the current study PEC and XYL LAGs and TMFRs did not differ significantly $(P<0.05)$ between the inoculums prepared from caecum contents of 36 (CC-36) and 78 day (CC-78) old rabbits, which confirms the observations of Gidenne et al. (2002) and Gidenne and Fortun-Lamothe (2002) that the microbial population is well adapted to these two substrates already at weaning and it remains active until slaughter. Furthermore, Marounek et al. (2000a) found a higher production of SCFA from pectin degradation in 28-dayold rabbits compared with 3-month (90 days)-old animals. Bindelle et al. (2007b) found higher maximum gas production and fractional rate of fermentation when sugar-beet pulp was incubated in inoculum prepared from young pig faeces compared with inoculums prepared from growing or adult pig faeces. Their findings are in agreement with our results, where the amount of gas produced in first $10 \mathrm{~h}$ of incubation and MFRs from PEC and XYL where higher in CC-36 than in CC-78. According to Le Goff et al. (2003) the faeces of young pigs contain relatively large amounts of (intestinally) unfermented carbohydrates, which enhance the bacterial activity in the inoculum and provoke higher gas production. We believe that the conclusion of Le Goff et al. (2003) is not valid for the fermentation in caecum. If the carbohydrates appear in the faeces of young animals then they were not fermented in the caecum. Consequently, the extent and intensity (MFR) of carbohydrate caecal fermentation should be lower in young animals than in adult animals. Further studies would be required to test this hypothesis.

The estimated kinetic parameters of STA incubated in CC-36 and CC-78 were opposite to those observed for PEC and XYL. Total potential gas production and maximum fermentation rate (MFR) was significantly higher and TMFR was significantly shorter when STA was incubated in CC-78. We suppose that low activity of starch degrading micro-organisms in young rabbits was a consequence of residual rabbit milk, which can negatively affect caecum fermentation. Rabbit milk fat contains antimicrobial compounds such as octanoic and decanoic acid (Canas-Rodriguez and Smith, 1966; Marounek et al., 1999), which can inhibit caecum fermentation. Under these circumstances reductive acetogenesis is a major characteristic of caecal fermentation in sucking rabbits (Piattoni et al., 1996; Marounek et al., 1999). In other words, caecal micro-organisms do not produce methane (gas) and carbon dioxide (gas) before weaning but considerable amounts of ammonia and acetic acid (Piattoni et al., 1996; Marounek et al., 1999), which are mainly dissolved in the liquid phase of incubation media. It seems that milk antimicrobial constituents switch the fermentation pattern of some types of micro-organisms such as starch fermenting micro-organisms, while others such as pectin and hemicellulose (xylan) fermenting micro-organisms remain mostly unaffected.

Gidenne and Fortun-Lamothe (2002) reported that cellulose-degrading micro-organisms are not present before day 15 (before weaning) and increase until day 36 . However, their activity remains very low also after their establishment in the caecum (Gidenne and FortunLamothe, 2002), which was observed in both inoculums in the current study. The pattern of NDF FEED fermentation was similar to the CEL. Prolonged CEL and NDF FEED LAGs and TMFRs in both inoculums suggest that neither of them has an important nutritional role for caecal microflora at any period of rabbit life.

\section{Conclusions}

In the first $10 \mathrm{~h}$ of fermentation that correspond to the normal retention time in the caecum (Gidenne et al., 2000), the highest amount of gas was produced from PEC followed by FEED and XYL. However, only with the former two substrates was TMFR short enough (less than $10 \mathrm{~h}$ ) to be almost completely fermented in vivo. The majority of gas thus derived from PEC, which represents a very important constituent of rabbit compound feeds.

The differences between older and weaned rabbits were significant in fermentation patterns of STA, PEC and XYL. In rabbits at weaning age the fermentation of PEC and XYL was more intensive (MFR), more rapid (TMFR) and the production of gas was higher than in rabbits at slaughter weight, where this pattern prevailed especially when STA was incubated.

\section{Acknowledgement}

The author would like to express his gratitude to Mrs Ajda Kermauner, M.Sc., for critically reading and commenting on the manuscript, and to Mrs Barbara Cimermančič and Mrs Helena Brdnik for all the work done during the in vitro fermentation trials. 


\section{References}

Akin DE and Chesson A 1989. Lignification as the major factor limiting forage feeding value. XVI International Grassland Congress, Nice, France, pp. 1753-1760.

Awati A, Konstantinov SR, Williams B, Akkermans ADL, Bosch MW, Smidt H and Verstegen MWA 2005. Effect of substrate adaptation on the microbial fermentation and microbial composition of faecal microbiota of weaning piglets studied in vitro. Journal of the Science of Food and Agriculture 85, 1765-1772.

Bauer E, Williams B, Bosch MW, Voigt C, Mosenthin R and Verstegen MWA 2004. Differences in microbial activity of digesta from three sections of the porcine large intestine according to in vitro fermentation of carbohydraterich substrates. Journal of the Science of Food and Agriculture 84, 2097-2104. Bennegadi N, Fonty G, Gidenne T and Licois D 2003. Effects of age and dietary fibre level on caecal microbial communities of conventional and specific pathogen-free rabbits. Microbial Ecology in Health and Disease 5, 23-32.

Beuvink JMW and Kogut J 1993. Modelling gas production kinetics of grass silages incubated with buffered ruminal fluid. Journal of Animal Science 71, 1041-1046.

Bidlack JE and Buxton DR 1992. Content and deposition rates of cellulose, hemicellulose, and lignin during regrowth of forage grasses and legumes. Canadian Journal of Plant Science 72, 809-818.

Bindelle J, Buldgen A, Boudry C and Leterme P 2007a. Effect of inoculum and pepsin-pancreatin hydrolysis on fibre fermentation measured by the gas production technique in pigs. Animal Feed Science and Technology 132, 111-122. Bindelle J, Buldgen A, Lambotte D, Wavreille J and Leterme P 2007b. Effect of pig faecal donor and pig diet composition on in vitro fermentation of sugar beet pulp. Animal Feed Science and Technology 132, 212-226.

Blas E, Cervera C and Fernandez-Carmona J 1994. Effect of two diets with varied starch and fibre levels on the performances of 4-7 weeks old rabbits. World Rabbit Science 2, 117-121.

Blümmel M, Makkar HPS and Becker K 1997. In vitro gas production: a technique revisited. Journal of Animal Physiology and Animal Nutrition 77, 24-34.

Calabro S, Nizza A, Pinna W, Cutrignelli MI and Piccolo V 1999. Estimation of digestibility of compound diets for rabbits using the in vitro gas production technique. World Rabbit Science 7, 197-201.

Canas-Rodriguez A and Smith HW 1966. The identification of antimicrobial factors of the stomach contents of suckling rabbits. Biochemical Journal 100, 79-82.

Edwards C 1993. Interactions between nutrition and the intestinal microflora. Proceedings of the Nutrition Society 52, 375-382.

Garcia J, Gidenne T, Falcao-E-Cunha L and De Blas C 2002. Identification of main factors that influence caecal fermentation traits in growing rabbits. Animal Research 51, 165-173.

Getachew G, Blümmel M, Makkar HPS and Becker K 1998. In vitro gas measuring techniques for assessment of nutritional quality of feeds: a review. Animal Feed Science and Technology 72, 261-281.

Gidenne T 1992. Effect of fibre level, particle size and adaptation period on digestibility and rate of passage as measured at the ileum and in the faeces in the adult rabbit. British Journal of Nutrition 67, 133-146.

Gidenne T 1997. Ceaco-colic digestion in the growing rabbit: impact of nutritional factors and related disturbances. Livestock Production Science 51, 73-88.

Gidenne $T$ and Fortun-Lamothe $L$ 2002. Feeding strategy for young rabbits around weaning: e review of digestive capacity and nutritional needs. Animal Science 75, 169-184.

Gidenne T, Pinheiro V and Falcao-E-Cunha L 2000. A comprehensive approach of the rabbit digestion: consequences of a reduction in dietary fibre supply. Livestock Production Science 64, 225-237.

Gidenne T, Jehl N, Segura M and Michalet-Doreau B 2002. Microbial activity in the caecum of the rabbit around weaning: impact of a dietary fibre deficiency and of intake level. Animal Feed Science and Technology 99, 107-118.

Gidenne T, Jehl N, Lapanouse A and Segura M 2004a. Inter-relationship of microbial activity, digestion and gut health in the rabbit: Effect of substituting fibre by starch in diets having high proportion of rapidly fermentable polysaccharides. British Journal of Nutrition 92, 95-104.
Gidenne T, Jehl N, Perez J-M, Arveux P, Bourdillon A, Mousset JL, Duperray J, Stephan S and Lamboley B 2005. Effect of cereal sources and processing in diets for the growing rabbit. II. Effects on performances and mortality by entheropathy. Animal Research 54, 65-72.

Gidenne T, Mirabito L, Jehl N, Perez J-M, Arveux P, Bourdillon A, Briens C, Duperray J and Corrent E 2004b. Impact of replacing starch by digestible fibre, at two levels of lignocellulose, on digestion, growth and digestive health of the rabbit. Animal Science 78, 389-398.

Gutiérrez I, Espinosa A, Garcia J, Caratano R and De Blas JC 2002. Effect of starch and protein sources, heat processing, and exogenous enzymes in starter diets for early weaned rabbits. Animal Feed Science and Technology 98, 175-186.

Hatfield RD 1989. Structural polysaccharides in forages and their degradability. Agronomy Journal 81, 39-46.

Kermauner A, Štruklec M and Marinšek Logar R 1996. Addition of probiotic to feed with different energy and ADF content in rabbits. 2 Effect on microbial metabolism in the caecum. World Rabbit Science 4, 195-200.

Lavrenčič A and Stefanon B 2001. Prediction of in situ degradability of dry matter and neutral detergent fibre of temperate forages with in vitro gas production and fibre fractions. Zootecnica e Nutrizione Animale 27, 179-192.

Lavrenčič A, Stefanon B and Susmel P 1997. An evaluation of the Gompertz model in degradability studies of forage chemical components. Animal Science 64, 423-431.

Le Goff G, Noblet J and Cherbut C 2003. Intrinsic ability of the faecal microbial flora to ferment dietary fibre at different growth stages of pigs. Livestock Production Science 81, 75-87.

Marounek M, Brezina P and Baran M 2000a. Fermentation of carbohydrates and yield of microbial protein in mixed cultures of rabbit caecal microorganisms. Archives of Animal Nutrition 53, 241-252.

Marounek M, Fievez V, Mbanzamihigo L, Demeyer D and Maertens L 1999. Age and incubation time effects on in vitro caecal fermentation pattern in rabbits before and after weaning. Archives of Animal Nutrition 52, 195-201.

Marounek M, Skrivanova V and Duškova D 2000b. In vitro caecal fermentation of nitrogenous substrates in rabbits. Journal of Agricultural Science 135, 437-442.

Marounek M, Vovk SJ and Benda V 1997. Fermentation patterns in rabbit caecal cultures supplied with plant polysaccharides and lactate. Acta Veterinaria Brno 67, 9-13.

Menke KH and Steingass H 1988. Estimation of the energetic feed value obtained from chemical analysis and in vitro gas production using rumen fluid. Animal Research and Development 28, 7-55.

Padilha MTS, Licois D, Gidenne T, Carre B and Fonty G 1995. Relationships between microflora and caecal fermentation in rabbits before and after weaning. Reproduction and Nutrition Development 35, 375-386.

Parrett AM, Edwards CA and Lokerse E 1997. Colonic fermentation capacity in vitro: development during weaning in breast-fed infants is slower for complex carbohydrates than for sugars. American Journal of Clinical Nutrition 65, 927-933.

Piattoni F, Demeyer D and Maertens L 1996. In vitro study of the age-dependent caecal fermantation pattern and methanogenesis in young rabbits. Reproduction and Nutrition Development 36, 253-261.

Statistical Analysis Systems Institute 1994. SAS/STAT user's guide, release 6.03 edition. SAS Institute, Cary, NC, USA.

Stefanon B, Pell AN and Schofield P 1996. Effect of maturity on water soluble forage fractions. Journal of Animal Science 74, 1104-1115.

Theodorou MK, Williams BA, Dhanoa MS, McAllan AB and France J 1994. A simple gas production method using a pressure transducer to determine the fermentation kinetics of ruminant feeds. Animal Feed Science and Technology 48, 185-197.

Venkateswaran K, Hattori N, La Duc MT and Kern R 2003. ATP as a biomarker of viable microorganisms in clean room facilities. Journal of Microbiological Methods 52, 367-377.

Williams B, Verstegen MWA and Tamminga S 2001. Fermentation in the large intestine of single-stomached animals and its relationship to animal health. Nutrition Research Reviews 14, 207-227.

Wilson JR 1994. Cell wall characteristics in relation to forage digestion by ruminants. Journal of Agricultural Science, Cambridge 122, 173-182. 